\title{
The puzzle of spontaneous versus traumatic intracranial hemorrhages
}

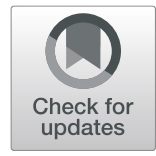

\author{
Gabriel Alexander Quiñones-Ossa', Yeider Durango-Espinosa², Huber Padilla-Zambrano ${ }^{3}$, \\ Luis Rafael Moscote-Salazar ${ }^{4}$, Ravish Keni ${ }^{5}$, Harsh Deora ${ }^{6}$ and Amit Agrawa ${ }^{5^{*}}$ (i)
}

\begin{abstract}
Intracerebral hemorrhage is hemorrhage occurring in the brain that can occur because of immediate trauma or structural disease process. The age-standardized mortality rate is decreasing worldwide especially in the past 20 years, but the number of cases and incidence along with number of disability-adjusted life-years and deaths keeps rising. Despite having half the incidence as ischemic stroke, intracerebral hemorrhage (traumatic or spontaneous) causes more morbidity and mortality than ischemic stroke and yet an established strategy for treatment on the lines of reperfusion therapy is a far-fetched dream. A selective review of all relevant articles covering recent treatment options and guidelines along with major emphasis of the surgical aspect and pathophysiology has been done. Complete literature review and differences between management of traumatic and spontaneous hemorrhage were sought and discussed. A pathophysiological basis of management should be followed for both these different yet similar pathologies. Understanding the etiology reveals a somewhat clearer picture regarding treatment of this highly unfortunate and devastating disease. Current interest is focused on the surgical management of the disease with the pathophysiology often been forgotten.
\end{abstract}

Keywords: Intracranial hemorrhage, Traumatic intracranial hemorrhage, Spontaneous hemorrhage

\section{Introduction}

Intracranial hemorrhage is the bleeding inside the brain parenchyma that may occur spontaneously or by an insult like trauma. It is a common disease with an approximate incidence of 25 per 100,000 persons every year [1]. It carries a lethal course due to the mechanical disruption of vessels leading to a neuronal injury with the subsequent activation of inflammatory cascade resulting in disruption of blood barrier and concomitant cerebral edema $[2,3]$ and obstruction in the cerebrospinal fluid flow causing cerebral herniation and death [4]. It is considered a medical emergency and rapid assessment and treatment after the diagnosis based on clinical presentation and its confirmation with neuroimaging studies

\footnotetext{
* Correspondence: dramitagrawal@gmail.com

${ }^{5}$ Department of Neurosurgery, All India Institute of Medical Sciences, Saket Nagar, Bhopal, Madhya Pradesh 462026, India

Full list of author information is available at the end of the article
}

is warranted to avoid clinical deterioration of the patient $[5,6]$ that could lead to unfavorable outcomes $[3,7]$. The objective of this narrative review is to provide a piece of general knowledge about the morbidity, mortality, types of intracranial hemorrhage, complications, and treatment and correlate it with the medical practice.

\section{Intracranial hemorrhage}

Intracranial hemorrhage ( $\mathrm{ICH})$ is a devastating disease $[1,3]$ that may be spontaneous (also known as nontraumatic intracranial hemorrhage) $(\mathrm{SICH})$ or due to a traumatic event $(\mathrm{TICH})[8,9]$. It is a life-threatening condition and a great cause of mortality and morbidity common in the adult population compared to the children [4, 9]. It has been accounted for $27 \%$ of strokes worldwide [10]. It is important to differentiate ICH types between traumatic and non-traumatic; when it is caused by non-traumatic bleeding, the physician must consider 
different etiologies such as arterial large and small-vessel disease, venous disease, and vascular malformation, and hemostatic disorders $[10,11]$. Also, it has been demonstrated that $\mathrm{TICH}$ is prevalent in younger populations (in older patients, falls are one of the highest causes) of head injuries and subsequent intracranial bleeding with a better prognosis when compared to the SICH [12].

As mentioned above, there are two types of $\mathrm{ICH}$ [12]. SICH precipitates in cases with deformed vasculature and especially in old people, it may be caused by vascular disturbance, hematological problems, and high-pressure onset $[3,11,12]$. While TICH occurs by a physical and traumatic event with a mechanism like contrecoup contusions by a violent movement of the brain within the cranium, the tensile strain and the brain itself overcomes the vascular resistance that leads to the hemorrhage or blood vessel disruption by shock waves secondary to the impact $[11,12]$. In fact, both types of ICH could have a sudden onset with a neurologic deficit, alteration in consciousness, headache, nausea, and vomiting as the first symptoms; also, patients might present with seizures episodes. The symptoms may be different based on the hematoma location, ataxia being a clear symptom of cerebellar hematoma while comatose status indicates a brain stem lesion or a compressive hematoma with mass effect [3].

\section{Traumatic or spontaneous intracranial hemorrhage Traumatic intracerebral hemorrhage (TICH)}

Traumatic brain injury (TBI) is a problem with global implications that will present multiple complications and fatal outcomes in patients; this is one of the main causes of mortality and disabilities worldwide [13-16]. One of the TBI main complications is the $\mathrm{TICH}$ known as the intracranial hemorrhage after a moderate or severe TBI $[15,17]$ occurs in 13 to $35 \%$ of patients after a traumatic event [18]. The increase of the $\mathrm{ICH}$ volume is presented in almost $40 \%$ of the cases, occurs within the first hours after the insult, and can lead to unfavorable outcomes (mass effect, refractory intracranial hypertension, and herniation); for this reason, it has an important impact on the prognosis and outcome of patients [19, 20]. The trauma severities, advanced age, multiple lesions, and midline deviation or cisternal compression are several factors associated with the $\mathrm{ICH}$ and hematoma growth [18].

\section{Spontaneous intracerebral hemorrhage (SICH)}

As previously mentioned the $\mathrm{SICH}$ is caused by an alteration in the vasculature and is common in the eldest population in most of the cases [12]. It is divided into two categories, the primary $\mathrm{SICH}$ that happens without a concomitant vascular malformation or coagulation problems and the secondary that occurs as a vascular malformation result $[3,11]$. The etiology may differ regarding the concomitant diseases being hypertension, cerebral amyloid angiopathy (CAA) [3], arteriovenous malformation (AVM), neoplasm, and aneurysmal bleed, the most common causes, even though there may be some other etiologies such as aneurysmal subarachnoid hemorrhage (ASH), hemorrhagic transformation of ischemic stroke (HTIS), venous sinus thrombosis, vasospasm, viral encephalitis, metabolic disorders, and neoplasm $[12,21]$. Most common sites of ICH related to the etiology are the external capsule of the putamen, the thalamus, pons, cerebellum, and lobar white matter with intraventricular extension [21].

\section{Hypertension}

Hypertension may be present in up to 70 to $90 \%$ of patients with ICH $[22,23]$. Microaneurysms of the lenticular striated branches of the middle cerebral artery, secondary to reactive hyperplasia of smooth muscle cells of cerebral arterioles and resulting collagen deposit, are usually broken $[2,21,24,25]$. The classic localization of these hemorrhages are the basal ganglia (35-40\%), thalamus (10-20\%), and cerebellar dentate nucleus and pons (5-10\%) [22-25]. It is not yet clear whether, at the time of presentation of the $\mathrm{ICH}$, if hypertension is a contributing factor, the cause or the result [22]; however, when the patient has a history of inadequately controlled hypertension, we could undoubtedly suspect that it could be the cause of the bleeding [24]. In non-contrast computed tomography (NCT), the observation of smooth-looking hematomas which are homogeneous, round, or oval and the association with a thin rim of edema which progressively can enlarge for several days after of the hemorrhage, with involvement of the periventricular white matter and the protuberance, producing irregular areas of hypo attenuation in the CT and the hyperintensity of T2 in the MRI is very suggestive that the $\mathrm{ICH}$ is secondary to a hypertensive microangiopathy $[2,24]$. The age of the patient is also an important factor to identify the etiology of ICH because for patients under 45 years of age, the causes of $\mathrm{ICH}$ are different from hypertension [2].

\section{Cerebral amyloid angiopathy}

Cerebral amyloid angiopathy (CAA) corresponds to 5$20 \%$ of all non-traumatic ICH in normotensive patients older than 55 years old [21], is a pathology that increases with age, and is the second most important risk factor for developing $\mathrm{ICH}$ after hypertension [2, 24]. In this condition, there is a deposition of amyloid- $\beta$ proteins in the capillaries, arterioles, and cortical arteries of small size; such deposition is rare in the brainstem and basal 
ganglia [26]. This produces a weakening of the vascular wall that can cause brain microbleeds $[1,2]$. The characteristic that distinguishes it from the hemorrhage related to hypertension is its lobar, cortical, or corticalsubcortical localization that affects individuals older than 55 years old who are normotensive; hemorrhages are often multiple and recurrent with extension to the subarachnoid space $[2,21,24]$.

\section{Aneurysmal subarachnoid hemorrhage}

Although it is clear that the most common etiology of SAH is of traumatic origin, among the nontraumatic causes, the rupture of a cerebral aneurysm represents up to $85 \%$ [2]. SAH represents $5-15 \%$ of all brain strokes, with an associated mortality of 12 to $66 \%$, but because the disease affects a considerable proportion of young patients and leads to the loss of productive life-years, this is so significant as the secondary to ischemic cerebral infarction, the most frequent among strokes as a public health problem [2, 27]. The commonly identified risk factors are female gender, smoking, and hypertension, and it is important to know that patients usually report a sudden onset of headache, which they describe as "the worst headache of their life" [2, 21, 28]. The diagnosis is made with a CT scan without contrast or with a lumbar puncture when the CT scan is negative and there is a high clinical suspicion [2]. Among the CT scan findings, we found higher density in basal cisterns, parenchymal hematoma, and massive appearance with a large filling defect and calcification [21]. Obliteration of the emergent aneurysm with surgical trimming or endovascular coiling is indicated to prevent rebleeding of the aneurysm, which makes a good result unlikely. When this is delayed, procoagulant therapy could be effective, since it reduces the risk of rebleeding [4].

\section{Hemorrhagic transformation of ischemic stroke}

Hemorrhagic transformation (HT) is a complication of acute ischemic stroke (AIS) and is any hemorrhage in the ischemic tissue observed in computed tomography $(\mathrm{CT})$ or magnetic resonance (MR). It is defined as "any degree of hyperdensity within the area of low attenuation" [29]. HT can be observed in the infarct area in many patients after the appearance of the AIS (from 2 to 40\%); furthermore, it is usually associated with greater morbidity and mortality [3, 21, 30]. Studies have shown some risk factors associated with $\mathrm{HT}$, among which are, aging, non-recanalization, hyperglycemia, anticoagulants, antiplatelet therapy, and fibrinolytic therapy [30-34]. The cause and pathophysiology of HT after ischemia is complex and is likely to involve damage to the blood-brain barrier (BBB) or reperfusion of ischemia (Tables 1 and 2) [17, 29].

\section{A patient in ER with $\mathrm{ICH}$}

ICH initial management is similar to the early ischemic stroke management (airway, cardiovascular, and coagulation problems management) [8], but in the $\mathrm{ICH}$, one of the main objectives is to determine the intracranial pressure, this could lead to a neurological worsening and fatal outcomes like disability or even death [4, 6, 9, 34]. But also, it is important to localize and approximate the volume of the hemorrhage to understand the impending cerebral injury risk and to establish the patient treatment [1]. The importance of the hematoma growth control is due to the high risk of the brain tissue compression or obstruction of the cerebrospinal fluid outflow that will lead to herniation and death $[4,9,35,36]$. The neuroimaging is useful to track the hematoma expansion and see the likelihood of a possible herniation [1, 21]. Also, it has been demonstrated that large intracranial blood volumes are related to higher mortality in the injured

Table 1 Etiology and most common locations of ICH [21]

\begin{tabular}{|c|c|}
\hline Etiology & Most frequent $\mathrm{ICH}$ locations \\
\hline Hypertensive bleed & $\begin{array}{l}\text { External capsule of the putamen, pons, thalamus, cerebellum, and } \\
\text { intraventricular extension from lobar white matter bleeding }\end{array}$ \\
\hline Cerebral amyloid angiopathy & Lobar, cortical, or subcortical hemorrhage \\
\hline Hemorrhagic ischemic stroke & Cortex and basal ganglia \\
\hline Aneurysmal subarachnoid hemorrhage & $\begin{array}{l}\text { Posterior communicating artery (PCA), anterior communicating artery } \\
(A C A), \text { middle cerebral artery trifurcation, basilar tip, and PICA (posterior } \\
\text { inferior cerebellar artery) }\end{array}$ \\
\hline $\begin{array}{l}\text { Cerebrovascular malformations: arteriovenous malformations (AVMs), } \\
\text { dural arteriovenous fistulas (DAVF), cavernous malformations, and dural } \\
\text { venous anomalies }\end{array}$ & Cavernous sinus, posterior fossa \\
\hline Venous thrombosis & Posterior temporal, parasagittal frontal, and parietal lobes \\
\hline Neoplasm hemorrhages & Depends on tumor location. \\
\hline Anticoagulant therapy & Supratentorial and intraparenchymal \\
\hline
\end{tabular}


Table 2 Differences between spontaneous and traumatic SAH [12]

\begin{tabular}{|c|c|c|}
\hline Etiology & $\mathrm{SICH}$ & $\mathrm{TICH}$ \\
\hline $\begin{array}{l}\text { Common age of } \\
\text { presentation }\end{array}$ & Elderly & Young or middle-aged \\
\hline Associated features & Intraventricular extension, SAH & Skull fracture, subdural extra-dural hemorrhage, SAH, contusion \\
\hline Clinical features & $\begin{array}{l}\text { Varies according to the location } \\
\text { of hematoma }\end{array}$ & $\begin{array}{l}\text { Disproportionate to the location of hematoma on account of associated multiple brain } \\
\text { injury and countercoup phenomenon }\end{array}$ \\
\hline Deep coma & Common & Less common \\
\hline $\begin{array}{l}\text { Seizures at } \\
\text { presentation }\end{array}$ & Less common & Common \\
\hline $\begin{array}{l}\text { Common location of } \\
\text { bleed }\end{array}$ & Subcortical > cortical & Cortical > subcortical \\
\hline Prognosis & $1 / 3$ have good outcomes & $2 / 3$ have good outcomes \\
\hline
\end{tabular}

patients [15]. Computed tomography scan (CT scan) is the most used neuroimaging test for the initial diagnosis but magnetic resonance imaging (MRI) is equally effective but takes more time [3, 37]. In order to detect secondary etiologies, the CT angiography and the MR angiography are used to establish conditions like AVMS or aneurysms as the etiology of the $\mathrm{ICH}$ in suspected patients [3, 37]. The CT scan is useful to determine whether there is or is not an $\mathrm{ICH}$ and the increase of the hemorrhage or hematoma volume that will produce a mass effect and refractory intracranial hypertension that will require a surgical intervention, $[2,19]$ while the MR is usually made to determine the cause of the hemorrhage [2].

\section{Intracranial pressure}

The pathophysiology of intracranial pressure is governed by the Monro-Kellie doctrine, which states that the total volume of intracranial contents is constant and that any increase in any of these components will initially fill a small potential space of only a few milliliters in volume, but then it must be compensated by a decrease in the volume of another intracranial component to avoid an increase in the ICP [38, 39]. There is a very close relationship between volume and intracranial pressure. Initially, the pressure increases slightly with the increase in volume, but when the system's damping mechanisms are exceeded, the ICP increases notably [40]. If the ICP approaches the mean arterial pressure (MAP), cerebral perfusion is compromised, leading to a secondary ischemic lesion [6]. We can measure intracranial pressure using devices that are inserted into the skull, by two mechanisms: ventricular catheter systems (IVC) and parenchymal catheter systems [26]. The AHA/ASA guide recommends the use of less invasive methods (such as raising the head of the bed to $30^{\circ}$, analgesia, and sedation to a state of calm and immobility, maintaining an optimal perfusion pressure between 50 to
$70 \mathrm{mmHg}$ ) at first place to decrease ICP $[6,26]$, and, if it is not successful, the start of more invasive measures [41].

In order to control the intracranial pressure, the mannitol is a common substance used in the cerebral swelling and herniation signs [4, 9], but it must be considered that repeated doses lead to hypovolemia due to the osmotic diuretic effect of mannitol [42]. Furthermore, the use of hypertonic solution could be more effective than mannitol [43, 44]. The aggressive reduction of blood pressure could control the hematoma growth and even the rebleeding in case the $\mathrm{ICH}$ is due to a broken aneurysm, but the reduction could lead to acute ischemia or infarction due to the low cerebral perfusion [3, 4, 9, 45-47].

\section{Blood pressure}

Following an ICH, an increase of blood pressure is common and has been described as an independent predictor of hematoma growth, perihematomal edema, and poor outcomes [6]. It has been documented that there is a zone of brain tissue at risk that if blood pressure drops precipitously, it could become ischemic due to the decrease in cerebral perfusion pressure. In addition, it is believed that acute hypertension (aHTN) worsens the growth of the hematoma $[6,48]$; this last situation is stronger for systolic BP $>175 \mathrm{mmHg}$ [6]. As described, there is still controversy about the exact objective of therapeutic blood pressure [26]. The guidelines recommend in acute $\mathrm{ICH}$ within $6 \mathrm{~h}$ of onset, the reduction of blood pressure (systolic objective $<140 \mathrm{mmHg}$ in $<1 \mathrm{~h}$ ) $[8,10,41]$. A randomized clinical trial where CT perfusion was used in small and medium ICH did not demonstrate a significant reduction in flow of blood within the perihematomal region related to early intensive reduction of blood pressure (BP) to a systolic blood pressure (SBP) target of $<140 \mathrm{mmHg}$ within several hours of $\mathrm{ICH}$ [49]. In a clinical cohort of 211 patients who received a standard protocol for BP reduction based on nicardipine 
to achieve a SBP target of $<160 \mathrm{mmHg}$ at an average of 30 mins (range, $15-45 \mathrm{~min}$ ) within $3 \mathrm{~h}$ after the start of the $\mathrm{ICH}$, the best results were observed in the group with the lowest SBP $(<135 \mathrm{mmHg})$ [50]. The AHA does not recommend a particular drug [41], but between the pharmacological arsenal to lower BP, we found nicardipine in infusion of 5 to $15 \mathrm{mg} / \mathrm{h}$, nitroprusside in infusion of $0.1-10 \mu \mathrm{g} / \mathrm{kg} / \mathrm{min}$, labetalol in bolus dose of 5 to $20 \mathrm{mg}$ every $15 \mathrm{~min}$ and infusion of $2 \mathrm{mg} / \mathrm{min}$, esmolol bolus $250 \mu \mathrm{g} / \mathrm{kg}$ or infusion $25-300 \mu \mathrm{g} / \mathrm{kg} / \mathrm{min}$, hydralazine $5-10 \mathrm{mg}$ every $30 \mathrm{~min}$ or infusion $1.5-5 \mu \mathrm{g} / \mathrm{kg} /$ min, enalapril $1.25-5 \mathrm{mg}$ each $6 \mathrm{~h}$, with $0.625 \mathrm{mg}$ IV as starting dose and nitroglycerin in infusion of $20-400 \mu \mathrm{g} /$ $\min [3,26]$.

\section{Seizures}

To manage the possible seizures is important to understand that early seizures occur within 1 week of the $\mathrm{ICH}$ and late seizures occur after the first week of the $\mathrm{ICH}$ onset [51], even if the seizures do not change the mortality or the eventual outcome, it is important to consider the long-term post seizures [6, 52, 53]. They usually occur in 8 to $15 \%$ of patients and may be the initial clinical manifestation in patients with ICH [3]. This is due to the acute disruption in the brain integrity with a biochemical alteration as the excessive release of neurotransmitters of excitatory nature and the blood degradation producing toxic effect that would lead to a cortical alteration $[54,55]$. In a clinical trial, 72 patients were randomized with valproic acid or placebo following a spontaneous ICH. They observed that patients treated with valproic acid were less likely to experience early seizures. However, there were no differences with respect to the general seizure rates in both groups during the 1year follow-up [56]. The guidelines do not recommend the use of antiepileptics routinely for the prevention of seizures after an ICH [10]. These seizures are usually treated with benzodiazepines or antiepileptic drugs [6].

\section{Fever}

Fever $\left(>38.3^{\circ} \mathrm{C}\right)$ may follow an $\mathrm{ICH}$ [3], it has been identified as a factor of poor results in these patients $[6,10]$. Frequently, no source of infection is identified [4], but this may be associated with sepsis, intraventricular hemorrhage (IVH), perihematomal inflammatory process, or subarachnoid propagation of the $\mathrm{ICH}$ [6]. Antipyretics may be used to reduce mild fever [8], but it has been shown that the routine use of paracetamol is not beneficial for thermal control [10, 57]. In animal models, induced hypothermia decreases some mediators such as thrombin and proinflammatory cytokines; this consequently decreases perihematomal edema [58]. External cooling devices may be used in some clinical settings but have not been shown to improve the results [10]. Although there is no benefit demonstrated controlling of fever, normothermia maintenance is logical and thus recommended to prevent secondary brain injury [8].

\section{Hemostatic therapy}

A hematoma usually spreads from an active hemorrhage, which is a predictor of poor results. Accordingly, patients with ICH could benefit from early hemostatic therapy [6]. In patients with coagulopathy, the prognosis of the ICH is worse, this should be reversed, due to the increase in the rate of expansion of the hematoma and the duration of that expansion [26]. In accordance with the above, it is necessary to remove anticoagulants as quickly as possible $[8,26]$. Literature indicates that clinical outcomes of $\mathrm{ICH}$ related to vitamin $\mathrm{K}$ antagonists (VKAs) are poor [4]. Therefore, VKA should be discontinued, and in patients with an elevated international normalized index (INR), rapid measures are necessary to reverse the effects of VKA $[8,10]$. Traditionally, for the correction of INR, vitamin $\mathrm{K}$ is administered intravenously at a dose of $5-10 \mathrm{mg}$, followed by fresh frozen plasma (FFP) at repeated doses until the INR is 1.4 or less and prothrombin complex concentrates (PCC) $[3,4$, 8, 26, 41]. The reversal of non-vitamin $\mathrm{K}$ antagonist oral anticoagulants (NOACs), such as dabigatran, is still under study [8]. Recently, idarucizumab, a monoclonal antibody designed to reverse the anticoagulant effects of dabigatran, has been introduced into medical practice as the first antidote for NOACs [59]. In the case of noncoagulopathic $\mathrm{ICH}$, the administration of procoagulant agents such as recombinant factor VIIa (rFVIIa) is still being studied [26]. A clinical trial showed that rFVIIa could restrict the growth of the hematoma but showed no improvement in clinical outcomes and increased the risk of arterial thromboembolic events [60]. Due to these results, its use is not recommended systematically unless it is for $\mathrm{ICH}$ associated with hemophilia with factor inhibitors [26].

\section{Surgical management}

If patients present with a small mass lesion or a midline shift less than $5 \mathrm{~mm}$, the patient should be managed with conservative management with close monitoring [31]; otherwise, as mentioned before, the increase of the intracranial hemorrhage that leads to a higher midline shift, the refractory high intracranial pressure, and the mass effect that would lead to a herniation require surgical management [19]. This treatment evacuates the hematoma and limits secondary insults and further complications; there are two common ways to do the surgical intervention: one is the open craniotomy with clot removal and the other one is the minimally invasive 
surgery that uses thrombolytics [3, 61]. The neurosurgical intervention must be considered in patients with neurological deterioration, loss of consciousness, and herniation or high intracranial pressure signs [7, 62].

A fronto-temporo-parietal craniotomy approach is suggested for the supratentorial bleeding with mass effect and midline shift [31]. Decompressive craniectomy approach is usually recommended for the edema and high intracranial pressure treatment that would help to drain the high blood volumes that lead to the previously mentioned midline shift [31, 63]. In subdural hematomas, the twist drill trephination, burr-hole trephination, craniotomy, decompressive subtemporal craniectomy, and a complete hemicraniectomy are recommended $[31,63]$.

\section{Outcomes}

The outcome is determined by multiple factors: etiology ( $\mathrm{SICH}$ or $\mathrm{TICH}$ ), age of the patient, depth of coma at presentation, and location of the hematoma. It is important to consider that patients who suffer an $\mathrm{ICH}$ are at high risk of a new vascular event [64]. In a previous study comparing traumatic and spontaneous $\mathrm{ICH}$, two thirds of all TICH patients had favorable outcomes, as determined using the GOS, compared to one third of patients having $\mathrm{SICH}$; this difference is accountable by virtue of younger age of $\mathrm{TICH}$ patients [21]. The rehabilitation in $\mathrm{ICH}$ patients is recommended.

\section{Investigations or current data}

There are certain minimum facilities necessary if one wants to treat a case of $\mathrm{ICH}$. These include teams of neurology, neuroradiology, neurosurgery, and critical care facilities, which need round the clock trained nurses and physicians [41, 64]. A routine part of the evaluation should be a severity score assessment of the patient along with relevant history and a quick but thorough examination. Since National Institutes of Health Stroke Scale (NIHSS) score can be of limited value in ICH patients, an externally validated score such as the $\mathrm{ICH}$ score is of value. A non-contrast computed tomography (NCCT) is a routinely available and recommended screening tool for ICH diagnosis as it has increased sensitivity to pick up acute hemorrhage. However identifying secondary causes of $\mathrm{SICH}$ such as underlying structural lesions including vascular malformations and tumors is imperative, and moreover, there is an assumption that hemorrhage in the basal ganglia and post fossa is due to hypertension and thus does not need further imaging. However, now with the availability of $\mathrm{CT}$ angiography (CTA), which is a widely available tool with minimal risk, every patient presenting with nontraumatic SAH should undergo CTA $[65,66]$. Also, radiological features such as presence of $\mathrm{SAH}$, a noncircular shape of hematoma, presence of edema out of proportion to the size of $\mathrm{ICH}$, unusual hemorrhage location, presence of mass lesion, or cord sign of venous sinus thrombosis should alert for the presence of a secondary cause and lead to more specific vascular imaging, the minimal being CTA and Catheter angiography being the gold standard for the same. Also, in a prospective analysis of 109 patients [67], it was found that CTA was able to detect DSA-positive pathologies causing acute spontaneous intracerebral hemorrhage in young (age between 18 and 45 years) or nonhypertensive patients with high positive and negative predictive values. Hematoma expansion is a strong predictor of mortality and eventual outcomes. The CTA spot sign is an important predictor of the same and has now a consensus definition and classification criteria (Table 3) [68].

There is an acute need for a standardized approach for imaging of acute $\mathrm{SICH}$, which will reduce the number of digital subtraction angiography (DSA) being unnecessarily performed while not compromising the rate of secondary $\mathrm{ICH}$ detection.

\section{Gaps in knowledge}

There are certain gaps in knowledge that remain despite best efforts. Epileptic seizures occur in $3-17 \%$ of patients but no evidence has emerged to show that prophylactic AED use leads to a better outcome. Also, patients of $\mathrm{SICH}$ are usually immobile and paretic and thus at high risk for DVT and pulmonary embolism. Consequently, the use of low molecular weight heparin is essential and has not shown any effect on hematoma growth [69]. CLOTS 1 reported 2518 stroke patients (232 with ICH) and eventually found that thigh-high compression stockings did not reduce DVT, pulmonary embolism (PE), or death [70]. CLOTS 2, however, reported that DVT was more common with below-knee graduated compression stockings compared to thigh-high graduated compression stockings [71]. CLOTS 3 had 2876 patients (376 with $\mathrm{ICH}$ ) and reported that intermittent pneumatic compression begun as early as the day of hospital admission reduced the occurrence of proximal DVT. More importantly, this effect was particularly prominent in patients with hemorrhagic stroke [72].

Dysphagia and aspiration can lead to aspiration pneumonitis. CHANT (cerebral hematoma and NXY treatment) was a trial to test the safety and tolerability of NXY-059 in patients with spontaneous ICH. At least 1 adverse event was reported in $88 \%$ of the placebotreated patients while $40 \%$ of ADEs were serious (i.e., resulted in prolonged hospitalization, were immediately life-threatening) or were fatal [73]. Concurrent stroke and MI were not uncommon. Data from the prospective Austrian Stroke Unit Registry included $4984 \mathrm{ICH}$ patients and found that $0.3 \%$ of patients had an MI over a median duration of 3 days. Consequently, a formal 
Table 3 Importance and interpretation of the CTA spot sign

\begin{tabular}{ll}
\hline Appearance & Spot-like or serpinginous appearance \\
\hline Location & Within the parenchymal hematoma without any outside communication \\
Density & Double Hounsfield units as compared to the surrounding hematoma \\
Number & Single or multiple \\
\hline
\end{tabular}

screening procedure for dysphagia needs to be performed in all patients before the initiation of oral intake to reduce the risk of pneumonia and systematic screening for myocardial ischemia or infarction with ECG and cardiac enzyme testing after ICH should be done [74].

An attempt at removal of ICH either by craniotomy or through a burr hole or via an endoscope or catheter is still controversial at best today. A recent metaanalysis of the three STICH (Surgical Trial in Intracerebral Haemorrhage-1, 2 and Trauma) Trials has probably defined a specialized subgroup of patients in a specific time period that may benefit from surgery. Mendelow has succinctly stated "Craniotomy is probably indicated for patients with superficial spontaneous lobar supratentorial hematoma when the level of consciousness drops below 13 within the first $8 \mathrm{~h}$ of the onset of hemorrhage" [75].

\section{Conclusions}

ICH location may specify the bleeding etiology, being the subdural and epidural hematomas due to traumatic injuries while the intraparenchymal, perimesencephalic, or subarachnoid bleedings may be due to a vascular etiology [4]. It is important to understand for the general practitioner the difference in the intracranial bleeding types in order to improve the initial management.

\section{Abbreviations}

ICH: Intracranial hemorrhage; SICH: Spontaneous intracranial hemorrhage; TICH: Traumatic intracranial hemorrhage; TBI: Traumatic brain injury; CTA: Computerized scan angiography

\section{Acknowledgements}

None

\section{Authors' contributions}

GAQO, YD-E, HP-Z, LRM-S, RK, HD and AA: conception, design of the work, acquisition, analysis, interpretation of data, drafted the work and substantively revised it. GAQO, YD-E, HP-Z, LRM-S, RK, HD and AA: Creation of new software used in the work. Not applicable. All the authors have approved the submitted version (and any substantially modified version that involves the authors' contributions to the study). All the authors have agreed both to be personally accountable for the authors' own contributions and to ensure that questions related to the accuracy or integrity of any part of the work, even ones in which the authors were not personally involved, are appropriately investigated, resolved, and the resolution documented in the literature.

\section{Funding}

None

Availability of data and materials

Not applicable.
Ethics approval and consent to participate

Not applicable

\section{Consent for publication}

Not applicable

\section{Competing interests}

"The author(s) declare(s) that they have no competing interests."

\section{Author details}

${ }^{1}$ Faculty of Medicine, Universidad El Bosque, Bogota, Colombia. ${ }^{2}$ Center for Biomedical Research (CIB), Faculty of Medicine-University of Cartagena, Cartagena de Indias, Colombia. ${ }^{3}$ Center for Biomedical Research (CIB), Cartagena Neurotrauma Research Group Research Line, Faculty of Medicine-University of Cartagena, Cartagena de Indias, Colombia. ${ }^{4}$ Neurosurgeon-Critical Care, Center for Biomedical Research (CIB), Research Line Cartagena Neurotrauma Research Group, Faculty of

Medicine-University of Cartagena, Cartagena de Indias, Bolivar, Colombia. ${ }^{5}$ Department of Neurosurgery, All India Institute of Medical Sciences, Saket Nagar, Bhopal, Madhya Pradesh 462026, India. 'Department of Neurosurgery, NIMHANS, Bangalore 560029, India.

Received: 27 May 2019 Accepted: 29 April 2020

Published online: 14 May 2020

\section{References}

1. Heit JJ, Iv M, Wintermark M. Imaging of intracranial hemorrhage. J Stroke. 2017;19:11-27.

2. Fischbein NJ, Wijman CA. Nontraumatic intracranial hemorrhage. Neuroimaging Clin N Am. 2010;20:469-92

3. Parker D, Rhoney DH, Liu-DeRyke X. Management of spontaneous nontraumatic intracranial hemorrhage. J Pharm Pract. 2010;23:398-407.

4. Naidech AM. Intracranial hemorrhage. Am J Respir Crit Care Med. 2011;184: 998-1006.

5. Heeley E, Anderson CS, Woodward M, et al. Poor utility of grading scales in acute intracerebral hemorrhage: results from the INTERACT2 trial. Int J Stroke. 2015;10:1101-7.

6. Schreuder FH, Sato S, Klijn CJ, Anderson CS. Medical management of intracerebral haemorrhage. J Neurol Neurosurg Psychiatry. 2017;88:76-84.

7. Salman RA-S, Labovitz DL, Stapf C. Spontaneous intracerebral haemorrhage. BMJ (Clinical research ed) 2009;339:b2586

8. Kim JY, Bae HJ. Spontaneous intracerebral hemorrhage: management Journal of stroke. 2017:19:28-39.

9. Zidan I, Ghanem A. Intracerebral hemorrhage in children. Alexandria J Med. 2012:48:139-45

10. Steiner T, Al-Shahi Salman R, Beer R, et al. European stroke organisation (ESO) guidelines for the management of spontaneous intracerebral hemorrhage. International journal of stroke : official journal of the International Stroke Society. 2014:9:840-55.

11. Nguyen HS, Doan N, Gelsomino M, Shabani S. Patients with blunt traumatic brain injury: a role for computed tomography angiography of the head to evaluate nontraumatic causes? World neurosurgery. 2017;101:506-8.

12. Siddique MS, Gregson BA, Fernandes HM, et al. Comparative study of traumatic and spontaneous intracerebral hemorrhage. J Neurosurg. 2002;96: $86-9$.

13. Mathers $C D$, Loncar D. Projections of global mortality and burden of disease from 2002 to 2030. PLoS Med. 2006;3:e442.

14. Norton R, Kobusingye O. Injuries. N Engl J Med. 2013;368:1723-30.

15. Perel P, Roberts I, Bouamra O, Woodford M, Mooney J, Lecky F. Intracranial bleeding in patients with traumatic brain injury: a prognostic study. BMC Emerg Med. 2009;9:15 
16. Quinones-Ossa G, Padilla-Zambrano H, Pal R, et al. Biomarkers in acute brain trauma: a narrative review. Journal of Acute Disease. 2019;8:1-6.

17. Lin WS, Lin TC, Hung Y, et al. Traumatic intracranial haemorrhage is in association with an increased risk of subsequent atrial fibrillation. Heart. 2017;103:1286-91.

18. Cepeda S, Gomez PA, Castano-Leon AM, Martinez-Perez R, Munarriz PM, Lagares A. Traumatic intracerebral hemorrhage: risk factors associated with progression. J Neurotrauma. 2015;32:1246-53.

19. Bullock MR, Chesnut R, Ghajar J, et al. Surgical management of traumatic parenchymal lesions. Neurosurgery 2006;58:S25-46; discussion Si-iv.

20. Chang EF, Meeker M, Holland MC. Acute traumatic intraparenchymal hemorrhage: risk factors for progression in the early post-injury period. Neurosurgery. 2006;58:647-56 discussion 647-656.

21. del Carpio R. Approach to non-traumatic intracerebral hemorrhage and differential diagnosis. 2014. Eur Congress Radiol:2014

22. Valentine D, Lord AS, Torres J, et al. How does preexisting hypertension affect patients with intracerebral hemorrhage? J Stroke Cerebrovasc Dis. 2019;28:782-8.

23. Zebian B, Critchley G. Spontaneous intracranial haemorrhage. Surg Oxford International Edition. 2012;30:136-41.

24. Kranz PG, Malinzak MD, Amrhein TJ. Approach to imaging in patients with spontaneous intracranial hemorrhage. Neuroimaging Clin N Am. 2018;28: 353-74.

25. Sessa M. Intracerebral hemorrhage and hypertension. Neurol Sci. 2008; 29(Suppl 2):S258-9.

26. Aguilar MI, Brott TG. Update in intracerebral hemorrhage. Neurohospitalist. 2011;1:148-59.

27. Ortega Zufiría JM, Calvo Alonso M, Lomillos Prieto N, et al. Hemorragia subaracnoidea aneurismática: avances clínicos. Neurología Argentina. 2017;9: 96-107.

28. D'Souza S. Aneurysmal subarachnoid hemorrhage. J Neurosurg Anesthesiol. 2015:27:222-40

29. Ge WQ, Chen J, Pan H, Chen F, Zhou CY. Analysis of risk factors increased hemorrhagic transformation after acute ischemic stroke. J Stroke Cerebrovasc Dis. 2018;27:3587-90.

30. Ozbek D, Ozturk Tan O, Ekinci G, Midi I. Risk of hemorrhage in ischemic stroke and its relationship with cerebral microbleeds. Clin Neurol Neurosurg. 2018;168:112-7.

31. Feinberg M, Mai JC, Ecklund J. Neurosurgical management in traumatic brain injury. Semin Neurol. 2015:35:50-6.

32. Landolfi A, Selvetella G, Cugino D, et al. Hemorrhagic transformation of acute ischemic stroke is limited in hypertensive patients with cardiac hypertrophy. Int J Cardiol. 2016;219:362-6.

33. Shoamanesh A, Kwok CS, Lim PA, Benavente OR. Postthrombolysis intracranial hemorrhage risk of cerebral microbleeds in acute stroke patients: a systematic review and meta-analysis. Int J Stroke. 2013;8:348-56.

34. Willmot M, Leonardi-Bee J, Bath PM. High blood pressure in acute stroke and subsequent outcome: a systematic review. Hypertension (Dallas, Tex : 1979). 2004:43:18-24

35. Davis SM, Broderick J, Hennerici M, et al. Hematoma growth is a determinant of mortality and poor outcome after intracerebral hemorrhage. Neurology. 2006;66:1175-81.

36. Morgenstern LB, Hemphill JC III, Anderson C, et al. Guidelines for the management of spontaneous intracerebral hemorrhage: a guideline for healthcare professionals from the American Heart Association/American Stroke Association. Stroke. 2010;41:2108-29.

37. van Asch CJ, Velthuis BK, Rinkel GJ, et al. Diagnostic yield and accuracy of CT angiography, MR angiography, and digital subtraction angiography for detection of macrovascular causes of intracerebral haemorrhage: prospective, multicentre cohort study. BMJ (Clinical research ed). 2015;351:h5762.

38. Godoy DA, Lubillo S, Rabinstein AA. Pathophysiology and management of intracranial hypertension and tissular brain hypoxia after severe traumatic brain injury: an integrative approach. Neurosurg Clin N Am. 2018:29:195-212.

39. Godoy DA, Videtta W, Di Napoli M. Practical approach to posttraumatic intracranial hypertension according to pathophysiologic reasoning. Neurol Clin. 2017;35:613-40.

40. Stocchetti N, Maas Al. Traumatic intracranial hypertension. N Engl J Med. 2014;370:2121-30

41. Hemphill JC 3rd, Greenberg SM, Anderson CS, et al. Guidelines for the management of spontaneous intracerebral hemorrhage: a guideline for healthcare professionals from the American Heart Association/American Stroke Association. Stroke. 2015:46:2032-60.

42. Dennis $L$, Mayer SA. Diagnosis and management of increased intracrania pressure. Neurol India. 2001;49(Suppl 1):S37-50.

43. Kamel H, Navi BB, Nakagawa K, Hemphill JC 3rd, Ko NU. Hypertonic saline versus mannitol for the treatment of elevated intracranial pressure: a metaanalysis of randomized clinical trials. Crit Care Med. 2011;39:554-9.

44. Koenig MA, Bryan M, Lewin JL 3rd, Mirski MA, Geocadin RG, Stevens RD. Reversal of transtentorial herniation with hypertonic saline. Neurology. 2008; 70:1023-9.

45. Anderson CS, Huang $Y$, Wang JG, et al. Intensive blood pressure reduction in acute cerebral haemorrhage trial (INTERACT): a randomised pilot trial. Lancet Neurol. 2008:7:391-9.

46. Bederson JB, Connolly ES Jr, Batjer HH, et al. Guidelines for the management of aneurysmal subarachnoid hemorrhage: a statement for healthcare professionals from a special writing group of the stroke council, American Heart Association. Stroke. 2009;40:994-1025.

47. Prabhakaran S, Gupta R, Ouyang B, et al. Acute brain infarcts after spontaneous intracerebral hemorrhage: a diffusion-weighted imaging study. Stroke. 2010;41:89-94.

48. Schellinger PD, Fiebach JB, Hoffmann K, et al. Stroke MRI in intracerebral hemorrhage: is there a perihemorrhagic penumbra? Stroke. 2003;34:1674-9.

49. Butcher KS, Jeerakathil T, Hill M, et al. The intracerebral hemorrhage acutely decreasing arterial pressure trial. Stroke. 2013;44:620-6.

50. Sakamoto $Y$, Koga M, Yamagami H, et al. Systolic blood pressure after intravenous antihypertensive treatment and clinical outcomes in hyperacute intracerebral hemorrhage: the stroke acute management with urgent riskfactor assessment and improvement-intracerebral hemorrhage study. Stroke. 2013;44:1846-51.

51. Bladin CF, Alexandrov AV, Bellavance $A$, et al. Seizures after stroke: a prospective multicenter study. Arch Neurol. 2000;57:1617-22.

52. de Greef BT, Schreuder FH, Vlooswijk MC, et al. Early seizures after intracerebral hemorrhage predict drug-resistant epilepsy. J Neurol. 2015;262: 541-6.

53. Neshige S, Kuriyama M, Yoshimoto T, et al. Seizures after intracerebral hemorrhage; risk factor, recurrence, efficacy of antiepileptic drug. J Neurol Sci. 2015;359:318-22.

54. Biffi A, Rattani A, Anderson CD, et al. Delayed seizures after intracerebral haemorrhage. Brain. 2016;139:2694-705.

55. Garrett MC, Komotar RJ, Starke RM, Merkow MB, Otten ML, Connolly ES. Predictors of seizure onset after intracerebral hemorrhage and the role of long-term antiepileptic therapy. J Crit Care. 2009;24:335-9.

56. Gilad R, Boaz M, Dabby R, Sadeh M, Lampl Y. Are post intracerebral hemorrhage seizures prevented by anti-epileptic treatment? Epilepsy Res. 2011;95:227-31.

57. den Hertog HM, van der Worp HB, van Gemert HM, et al. The paracetamol (acetaminophen) in stroke (PAIS) trial: a multicentre, randomised, placebocontrolled, phase III trial. Lancet Neurol. 2009;8:434-40.

58. Kollmar R, Staykov D, Dorfler A, Schellinger PD, Schwab S, Bardutzky J. Hypothermia reduces perihemorrhagic edema after intracerebral hemorrhage. Stroke. 2010;41:1684-9.

59. Pollack CV Jr, Reilly PA, Eikelboom J, et al. Idarucizumab for dabigatran reversal. N Engl J Med. 2015:373:511-20.

60. Mayer SA, Brun NC, Begtrup K, et al. Efficacy and safety of recombinant activated factor VII for acute intracerebral hemorrhage. N Engl J Med. 2008; 358:2127-37.

61. Qureshi Al, Mendelow AD, Hanley DF. Intracerebral haemorrhage. Lancet (London, England). 2009;373:1632-44.

62. Steiner $T$, Kaste $M$, Forsting $M$, et al. Recommendations for the management of intracranial haemorrhage - part I: spontaneous intracerebra haemorrhage. The European Stroke Initiative Writing Committee and the Writing Committee for the EUSI Executive Committee Cerebrovascular diseases (Basel, Switzerland). 2006;22:294-316

63. Pascual JM, Prieto R. Surgical management of severe closed head injury in adults. Schmidek and sweet operative neurosurgical techniques: Elsevier. 2012:1513-1538.

64. Biffi A, Anderson CD, Battey TW, et al. Association between blood pressure control and risk of recurrent intracerebral hemorrhage. Jama. 2015;314:904-12.

65. Alobeidi F, Aviv RI. Emergency imaging of intracerebral haemorrhage. Front Neurol Neurosci. 2015;37:13-26. 
66. Wong GK, Siu DY, Abrigo JM, et al. Computed tomographic angiography and venography for young or nonhypertensive patients with acute spontaneous intracerebral hemorrhage. Stroke. 2011;42:211-3.

67. Wada R, Aviv Rl, Fox AJ, et al. CT angiography "spot sign" predicts hematoma expansion in acute intracerebral hemorrhage. Stroke. 2007;38:1257-62.

68. Thompson AL, Kosior JC, Gladstone DJ, et al. Defining the CT angiography 'spot sign' in primary intracerebral hemorrhage. The Canadian journal of neurological sciences Le journal canadien des sciences neurologiques. 2009; 36:456-61.

69. Orken DN, Kenangil G, Ozkurt H, et al. Prevention of deep venous thrombosis and pulmonary embolism in patients with acute intracerebral hemorrhage. Neurologist. 2009;15:329-31.

70. Dennis M, Sandercock PA, Reid J, et al. Effectiveness of thigh-length graduated compression stockings to reduce the risk of deep vein thrombosis after stroke (CLOTS trial 1): a multicentre, randomised controlled trial. Lancet (London, England) 2009:373:1958-1965.

71. Thigh-length versus below-knee stockings for deep venous thrombosis prophylaxis after stroke: a randomized trial. Ann Intern Med. 2010;153:553-62.

72. Dennis M, Sandercock P, Reid J, Graham C, Forbes J, Murray G. Effectiveness of intermittent pneumatic compression in reduction of risk of deep vein thrombosis in patients who have had a stroke (CLOTS 3): a multicentre randomised controlled trial. Lancet (London, England). 2013:382:516-24.

73. Messe SR, Sansing LH, Cucchiara BL, Herman ST, Lyden PD, Kasner SE. Prophylactic antiepileptic drug use is associated with poor outcome following ICH. Neurocrit Care. 2009;11:38-44.

74. McKinney JS, Cheng JQ, Rybinnik I, Kostis JB. Comprehensive stroke centers may be associated with improved survival in hemorrhagic stroke. J Am Heart Assoc. 2015;4.

75. Mendelow AD. Surgical craniotomy for intracerebral haemorrhage. Front Neurol Neurosci. 2015;37:148-54.

\section{Publisher's Note}

Springer Nature remains neutral with regard to jurisdictional claims in published maps and institutional affiliations.

\section{Submit your manuscript to a SpringerOpen ${ }^{\circ}$ journal and benefit from:}

- Convenient online submission

- Rigorous peer review

- Open access: articles freely available online

High visibility within the field

- Retaining the copyright to your article

Submit your next manuscript at $\boldsymbol{\nabla}$ springeropen.com 